H. C. SEFTEL ET $A L$. : OSTEOPOROSIS, SCURVY, AND SIDEROSIS IN JOHANNESBURG BANTU

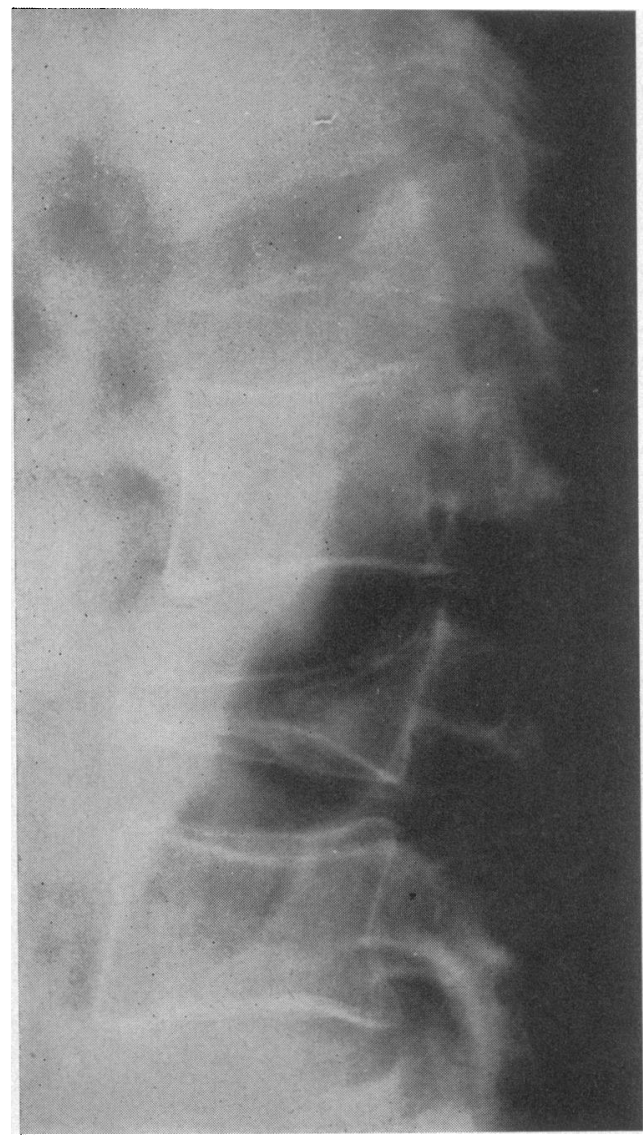

FIG. 1

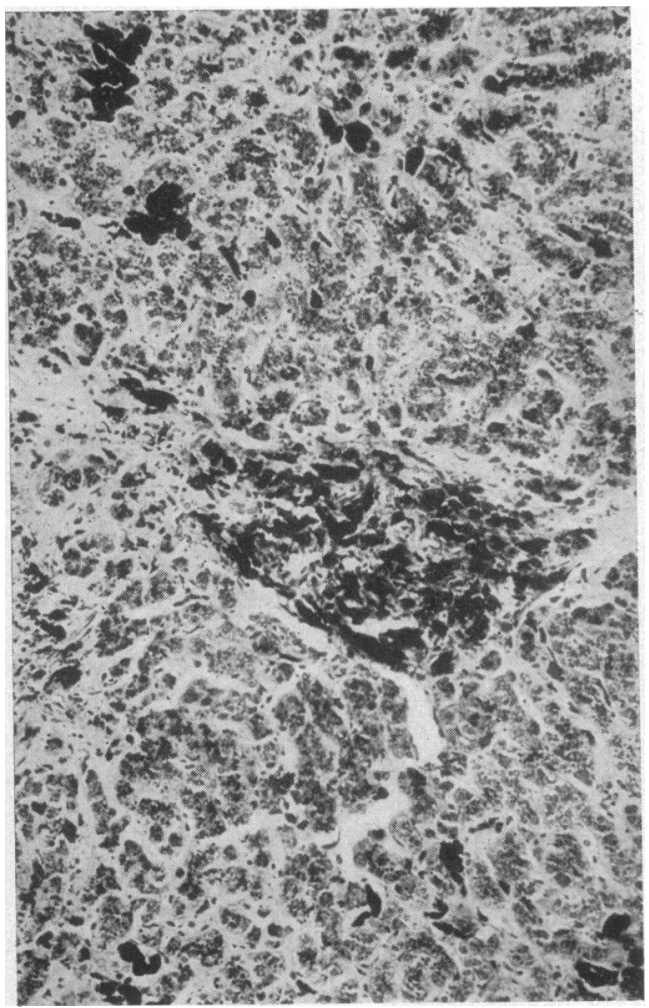

FIG. 3.-Section of liver showing heavy deposits of iron in parenchymal cells, Kupffer cells, and portal tracts. (Perls's stain. $\times 100$.)

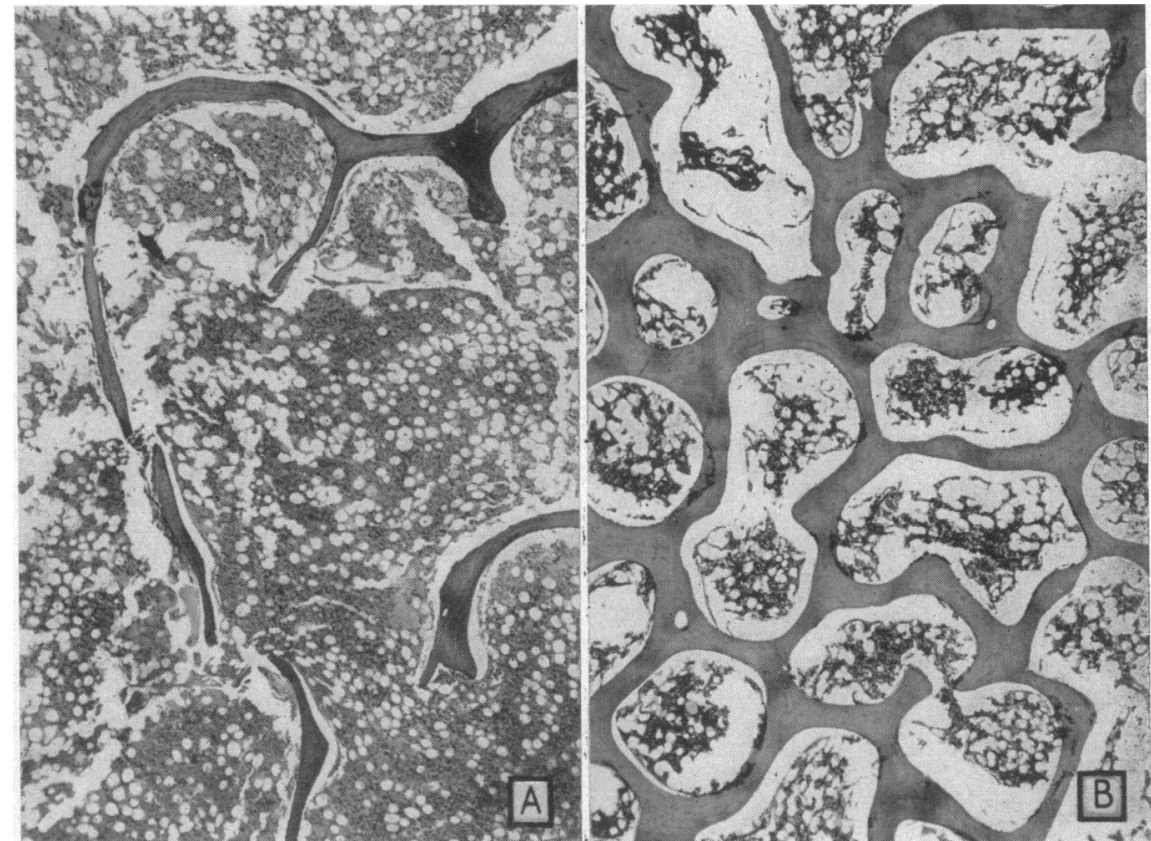

FIG. 2

FIG. 1.-X-ray plate of the lumbar spine of a Bantu male with severe siderosis, showing a marked diminution in bone density and vertebral collapse.

Fig. 2A.-Section of iliac crest bone from osteoporotic subject showing thin trabeculae and widened marrow spaces. (H. and $\mathrm{E} . \quad \times 18$.)

FIG. 2B.-Section of iliac crest bone from control subject showing normal trabeculae and marrow spaces. (H. and E. $\times 18$.)

\section{E. DENT AND L. WATSON: HYPERPARATHYROIDISM AND SARCOIDOSIS}

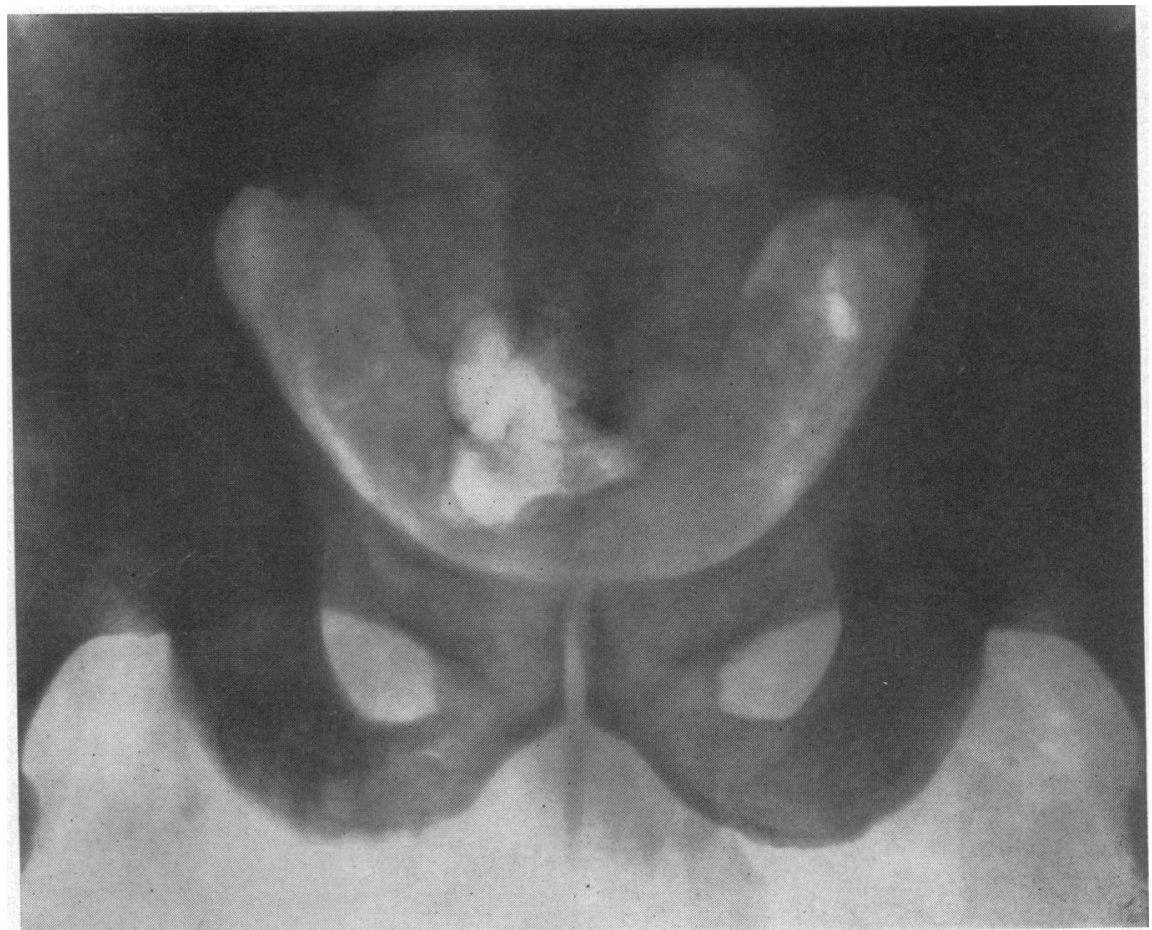

$X$-ray film of pelvis taken on 12 December 1964. Note the abnormal appearance of the

$\mathrm{X}$-ray fight pubic ramus and ischium, discussed further in the text.

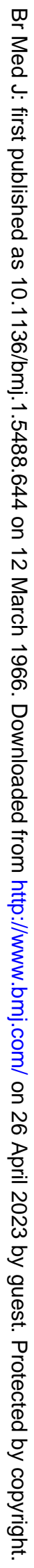


effect. Even a small decrease in absorption would be important, since the calcium intake in adult Bantu is usually less than $500 \mathrm{mg}$. daily (Walker, 1965). While the low levels of calcium in the serum and urine of a number of our osteoporotic subjects would be compatible with diminished absorption from the gut, as yet no direct confirmatory evidence for this has been obtained.

The possibility that the osteoporosis may be the result of chronic ascorbic acid deficiency, and that this deficiency is in turn a function of the severe siderosis, deserves consideration. The association of osteoporosis with scurvy is well recognized, and probably relates to the role of ascorbic acid in the formation of collagen and hence new bone (Vilter, 1954). In Johannesburg scurvy occurs almost exclusively in Bantu adults with severe siderosis, and is extremcly rare in infants, even when gross malnutrition is present (Trowell, 1960). This suggests that siderosis may play a part in the production of the scurvy. Evidence in favour of this thesis was first obtained in 1962 by Schulz and Swanepoel, who reported the results of ascorbic acid "saturation" tests in two Bantu patients with severe siderosis and scurvy. They found that urinary excretion of ascorbic acid remained very low after repeated administration of large oral doses of the vitamin, and in one patient this was also noted after parenteral loading. It is known from in vitro studies that ferric iron accelerates the oxidative catabolism of ascorbic acid (Mazur et al., 1960), and Schulz and Swanepoel therefore suggested that the massive ferric deposits in severely siderotic Bantu might act likewise. If this were so then it would be anticipated that ascorbic-acid loading would be followed by an increased passage of its oxidation products in the urine.

Recently we have confirmed and extended the observations of Schulz and Swanepoel (1962) by showing that ascorbic-acid loading of siderotic Bantu is associated not only with a low urinary excretion of the vitamin but also with an increased excretion of the end-product oxalic acid (Seftel et al., 1964). If ascorbic-acid deficiency does play a part in the production of osteoporosis in the Bantu it will be the first time that such an association has been established in adults. Previously it has been documented adequately only in children and experimental animals (Vilter, 1954 ; Höjer, 1923).

\section{Summary}

The clinical, radiological, biochemical, and pathological features of 32 Bantu patients with severe spinal osteoporosis are described. The condition has been found to differ strikingly from the usual forms of osteoporosis encountered in white subjects. Firstly, the majority of the affected patients were middle-aged men. Secondly, a significant proportion exhibited the features of classical acute scurvy. Thirdly, the condition was almost invariably associated with severe siderosis. Possible reasons for the association between osteoporosis, scurvy, and siderosis are discussed.

We wish to thank the Superintendent of Baragwanath Hospital for permission to publish, the Director of the South African Institute for Medical Research for facilities granted, and Mr. M. Ulrich for the photomicrographs.

[Reprint requests to be addressed to Dr. H. Seftel, Department of Medicine, Medical School, Hospital Street, Johannesburg, South Africa.]

\section{REFERENCES}

Bothwell, T. H., and Bradlow, B. A. (1960). Arch. Path., 70, 279. Jacobs, P., Keeley, K. J., Kramer, S, Seftel, H. C., and Zail, S. (1964a). Brit. F. Haemat., 10, 50.

and Isaacson, C. (1962). Brit. med. F., 1, 522

Seftel, H. C., Jacobs, P., Torrance, J. D., and Baumslag, N. 1964b). Amer. 7. clin. Nutr., 14, 47

Delbarre, F. (1960). Sem. Hôp. Paris, 36, 576.

Fourman, P. (1960). Calcium Metabolism and the Bone. Blackwell, Oxford.

Grusin, H., and Kincaid-Smith, P. S. (1954). Amer. f. clin. Nutr., 2, 323.

- and Samuel, E. (1957). Ibid., 5, 644.

Hartley, W. J., Mullins, J., and Lawson, B. M. (1959). N.Z. vet. F., 7, 99.

Higginson, J., Gerritsen, T., and Walker, A. R. P. (1953). Amer. F. Path., $29,779$.

Hiyeda, K. (1939). Fap. F. med. Sci., 4, 91.

Hö er, J. A. (1923). Acta paediat. (Uppsala), 3, Suppl., p. 48

MacDonald, R. A. (1964). Hemochromatosis and Hemosiderosis.

Manis, J., and Schachter, D. (1964). Amer. F. Physiol., 207, 893.

Manis, J., and Schachter, D. (1964). Amer. F. Physiol., 207, 893. Nesterov, A. I. (1964). Arthr. and Rheum., 7, 29.

Nordin, B. E. C. (1961). Lancet, 1, 1011.

- and Fraser, R. (1960). Ibid., 1, 947.

Novellie, L. (1964). In Johannesburg Kaffir Beer Research ProjectPsychological, Nutritional and Sociological Studies of Kaffir Beer. South African Council for Scientific and Industrial Research, Pretoria.

Saville, P. D. (1965). 7. Bone ft Surg., 47 A, 492.

Schulz, E. J., and Swanepoel, H. (1962). S. Afr. med. F., 36, 367.

Seftel, H. C., Charlton, R W., Jacobs, P., and Bothwell, T. H. (1964). S. Afr. F. med. Sci., 29, 97.

Trowell, H. C. (1960). Non-infective Disease in Africa. Arnold, London.

Vilter, R. W. (1954). In The Vitamins, edited by W. H. Sebrell and R. S. Harris, vol. 1. Academic Press, New York.

Walker, A. R. P. (1965). Amer. F. clin. Nutr., 16, 327.

and Arvidsson, U. B. (1953). Trans, roy. Soc. trop. Med. Hyg., $47,536$.

Strydom, E. S. P., Reynolds, P. A., and Crobbelaar, B. G. (1955).

S. Afr. F. Lab. clin. Med., 1, 254.

\title{
Hyperparathyroidism and Sarcoidosis
}

\author{
C. E. DENT,* M.D., F.R.C.P.; LYAL WATSON,* M.B., F.R.A.C.P.
}

[With Special Plate]

Brit. med. F., 1966, 1, 646-649

The characteristic clinical features of a raised plasma calcium are now well known and in consequence the diagnosis of hypercalcaemia is being made with increasing frequency. Cases have also been described in which it has been found more or less by accident in individuals who are completely free of hypercalcaemic symptoms or signs. This happened in the case reported here.

Whatever the mode of presentation the cause of the hypercalcaemia can usually be established with certainty. Difficulty

* Member of the Medical Unit, University College Hospital, London. arises, however, in patients who are found to have more than one of the known possible causes of a raised plasma calcium. We referred to this problem recently when we reported the case of a patient who proved to have both primary carcinoma of the cervix uteri and primary hyperparathyroidism due to a parathyroid adenoma (Dent and Watson, 1964), and we added that this complex situation seemed to have occurred more often than it should.

Reviewing his experience in the first 80 patients with primary hyperparathyroidism treated at University College Hospital, one of us (Dent, 1962) listed the other diseases found associated 
with the hyperparathyroidism. He also quoted the case of a patient of Professor M. L. Rosenheim who had died of renal failure and sarcoidosis and in whom a parathyroid tumour was found at necropsy, commenting that this association had been reported before (Snapper et al., 1958 ; Burr et al., 1959) and gave food for thought. We have now treated 140 patients with primary hyperparathyroidism, and it is of interest that four of these suffered at the same time from a second condition which is known to produce hypercalcaemia-two had thyrotoxicosis (Dent and Parfitt, in preparation), one (referred to above) had carcinoma of the cervix uteri (Dent and Watson, 1964), and one, the subject of the present report, had biopsy-proved sarcoidosis.

\section{Case Report}

A married man aged 44 , who had been in good health throughout his life, was admitted to University College Hospital in December 1964. He was referred by Dr. H. Kopelman, of Epping, who had first seen him in 1961, when he complained of chest pain. An $x$-ray film taken at that time was thought to be normal, and as the pain soon cleared up he was not given any treatment.

$\mathrm{He}$ remained well, but in June 1964 a routine chest $x$-ray examination showed diffuse miliary mottling of his lungs. He was seen by Dr. V. U. Lutwyche, consultant chest physician, of Harlow. A small gland was removed from the left axilla and showed typical histological changes of sarcoidosis. Other investigations performed at that time showed that the haemoglobin, E.S.R., plasma proteins and electrophoretic pattern, bilirubin, urea, and empirical liverfunction tests were all normal. On the other hand, his plasma calcium was $16.4 \mathrm{mg} . / 100 \mathrm{ml}$., plasma phosphorus $2.1 \mathrm{mg} . / 100 \mathrm{ml}$, and plasma alkaline phosphatase 23 K.A. units. $X$-ray films of the bones were thought to show no abnormality.

He was treated with prednisone $20 \mathrm{mg}$. daily for three weeks, at the end of which his plasma calcium was still $15 \mathrm{mg} . / 100 \mathrm{ml}$. Cortisone $150 \mathrm{mg}$. daily was substituted for the next two weeks, followed by $100 \mathrm{mg}$. daily for a further two weeks. Antituberculous drugs were also given for several weeks during steroid administration. His plasma calcium remained essentially unchanged throughout. As he had developed glycosuria and a glucose-tolerance test was abnormal, steroids were then stopped, and one month later his plasma calcium was still $15.2 \mathrm{mg} . / 100 \mathrm{ml}$.

When first seen at University College Hospital as an out-patient at the end of October 1964 he said that he had no symptoms at all. Careful questioning, however, elicited some minor complaints, including occasional tiredness and dull headaches recently, breathlessness on exertion for about six months, and occasional nocturia for about two years. His wife thought he had become rather badtempered during the last year or so. There was no anorexia, nausea, or vomiting, no thirst or loss of weight, and no pain. He was a fit-looking man, height $177 \mathrm{~cm}$. (5 ft. $10 \mathrm{in}$.), weight $66 \mathrm{~kg}$. (145 lb.), who showed no abnormalities on systematic physical examination apart from a slightly raised blood-pressure (160/105). There was no corneal calcification. Investigations at that stage fully confirmed the findings at Harlow Hospital. When he was admitted to the metabolic ward in December 1964 his symptoms and signs showed no change from those of the previous October.

\section{Initial Investigations}

Plasma calcium $14.7 \mathrm{mg} . / 100 \mathrm{ml}$., plasma phosphorus $1.9 \mathrm{mg} . /$ $100 \mathrm{ml}$., plasma alkaline phosphatase $28 \mathrm{~K}$. A. units, plasma urea $37 \mathrm{mg} . / 100 \mathrm{ml}$., plasma sodium $136 \mathrm{mEq} / \mathrm{l}$., plasma potassium 4.6 $\mathrm{mEq} / 1$., plasma chloride $106 \mathrm{mEq} / 1$, plasma bicarbonate $22 \mathrm{mEq} / 1$., plasma total proteins $7.3 \mathrm{~g} . / 100 \mathrm{ml}$., plasma protein electrophoresis showed no abnormality, haemoglobin 16.5 g./100 ml., E.S.R. 10 $\mathrm{mm}$. in one hour, urinary calcium excretion $348 \mathrm{mg} . / 24$ hours, maximum urinary specific gravity after overnight water deprivation 1010 , chemical and microscopical examination of a clean specimen of urine revealed no abnormality. The Mantoux test was positive $1 / 10,000$, F.E.V., /F.V.C. $=74 \%$, vital capacity 4.25 1., Dco 14.6 $\mathrm{ml} . / \mathrm{mm}$. $\mathrm{Hg} / \mathrm{min}$. at rest and 16.9 after exercise. Bromsulphalein retention was $1 \%$ after 45 minutes, plasma alkaline phosphatase electrophoresis showed that it was of the "bone-type" (Dr. M.
Newton), and iliac-crest biopsy showed appearances which were consistent with a diagnois of either hyperparathyroidism or Paget's disease of bone (Dr. P. Byers).

$X$-ray films showed that the kidneys were of normal size and there was a dense shadow, probably a renal stone, in the lower pole of the right kidney. There were multiple fine nodular opacities in both lung fields with calcification at the left hilar region. The skeletal $x$-ray films were interesting. The hands showed minor but definite changes with some erosion of the terminal phalanges, and small areas of subperiosteal erosion in the middle phalanges, which were thought to indicate hyperparathyroid bone disease. The pelvis is shown in the Special Plate. The right pubic ramus and ischium were somewhat expanded and the normal architecture was replaced by a coarsely trabeculated appearance, the abnormal area having a fairly clear demarcation from surrounding normal bone. It was considered that these appearances were more consistent with a diagnosis of Paget's disease of bone than hyperparathyroid bone disease. The skull had a somewhat mottled appearance and had lost its table differentiation. The other bones were normal.

\section{Further Investigations and Progress}

At this stage of the investigation it was clear that the patient had sarcoidosis and hypercalcaemia and it seemed that the hypercalcaemia did not respond to the administration of steroids. However, it was thought necessary to repeat the administration of steroids, and he was given hydrocortisone $120 \mathrm{mg}$. daily-an amount equivalent to the initial dose of cortisone which he had previously. It was also decided to perform this investigation under balance control.

Accordingly he was given a constant diet containing $1,050 \mathrm{mg}$. of calcium and $1,333 \mathrm{mg}$. of phosphorus daily. After stabilization on this diet for five days the calcium and phosphorus balances were determined for two consecutive six-day periods. These showed that there was good gastro-intestinal absorption of calcium with a daily faecal calcium of about $700 \mathrm{mg}$. However, as the urinary calcium was constantly above $500 \mathrm{mg}$./day, he was in negative calcium balance of between 150 and $200 \mathrm{mg}$./day. The phosphorus balance was also negative to about the same degree.

Hydrocortisone $40 \mathrm{mg}$. was then given every eight hours and continued for 18 days, during which three more six-day balance periods were obtained on the same diet. The daily faecal calcium excretion showed an average increase of about $100 \mathrm{mg}$. during hydrocortisone administration. Initially the urinary calcium excretion also rose by about $100 \mathrm{mg}$./day, but returned to the baseline level of about $500 \mathrm{mg}$./day during the third hydrocortisone period. Thus the calcium balance became more negative during hydrocortisone administration, reaching an overall external loss of about 350 $\mathrm{mg}$./day during the first 12 days and falling to about $250 \mathrm{mg}$./day during the next six days.

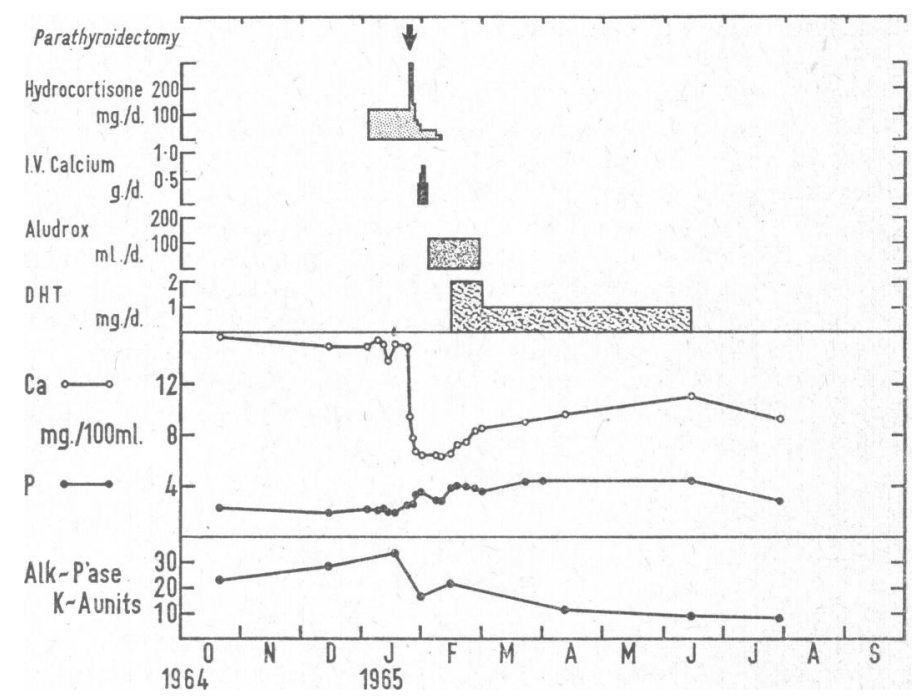

Metabolic data. Note that the plasma calcium and phosphorus levels did not alter significantly during hydrocortisone administration, but both became normal after parathyroidectomy and treatment with dihydrotachysterol. The plasma alkaline phosphatase levels also returned to normal. 
The plasma calcium and phosphorus levels were determined at regular intervals throughout the investigation and they are shown, together with the plasma alkaline phosphatase levels and some other data, in the Chart. The plasma calcium and phosphorus levels remained substantially unchanged throughout hydrocortisone administration in spite of the change in calcium balance. After a slight rise and fall the plasma calcium at the end of the test was almost exactly the same as it had been at the beginning. This is how most patients with primary hyperparathyroidism behave.

At this stage of the investigation it therefore seemed clear that the hypercalcaemia in this patient was not due to sarcoidosis. Furthermore, all the evidence (lack of response to hydrocortisone, radiological features, and the balance picture) all pointed to the presence of primary hyperparathyroidism as a second diagnosis. $\mathrm{He}$ still looked and felt well, but his plasma calcium was considerably raised, he had. gross hypercalcuria, and there was radiological evidence of a stone in the right kidney. We felt that his prognosis was bad if left untreated, so it was decided to explore his neck.

\section{Operation and Post-operative Course}

On 25 January 1965 Mr. D. R. Davies removed a parathyroid adenoma weighing $10.5 \mathrm{~g}$. and also identified three normal parathyroid glands in the neck. Histological examination by frozen sections at the time, and later from the paraffin sections, showed that the adenoma was of the chief-cell type and confirmed the normality of the other three parathyroid glands (Professor J. Smith).

Surgically he made a satisfactory recovery from the operation, the wound healing quickly and completely. On the other hand, he soon became hypocalcaemic, with severe tetany, depression, and other mental symptoms. We were not expecting such severe tetany in the apparent absence of severe bone disease. On the fourth post-operative day treatment was begun with intravenous calcium gluconate, followed later by Aludrox $30 \mathrm{ml}$. four times daily by mouth, and dihydrotachysterol $1 \mathrm{mg}$. twice daily. The dose of hydrocortisone, increased to $300 \mathrm{mg}$. daily for two days to cover the operation, was also progressively lowered and then stopped altogether during this period (see Chart). His plasma calcium then slowly rose to $8.4 \mathrm{mg} . / 100$ ml. on 1 March, when he had recovered almost completely from his post-operative symptoms and was discharged from hospital to continue taking dihydrotachysterol $1 \mathrm{mg}$. daily as sole treatment.

His condition remained very satisfactory during the follow-up, which also provided several findings of note. His plasma calcium rose to normal by $22 \mathrm{March}$ and then slowly rose further to 11 $\mathrm{mg} . / 100 \mathrm{ml}$. on 14 June, when he was quite free of symptoms. Dihydrotachysterol was therefore stopped. Seven weeks later his plasma calcium was again normal (see Chart). His plasma phosphorus remained normal throughout the follow-up period. On 20 March he had an episode of right-sided renal colic, and $x$-ray examination on 22 March showed that the stone in the right kidney had shifted to the right ureter. Another $x$-ray film on 23 June showed no evidence of this stone, which was presumed to have been passed without further symptoms.

The plasma alkaline phosphatase levels fell to $11 \mathrm{~K} . \mathrm{A}$. units on 12 April and to 8 K.A. units on 2 August, and this steady fall to normal levels is of particular interest in relation to his bone $x$-ray films. On 23 June the hands were normal, with complete resolution of the minor but definite changes of hyperparathyroid bone disease seen before operation. An $x$-ray film of the pelvis was also taken. There had been some filling in of the coarsely trabeculated pattern previously seen in the right pubic ramus and ischium and areas of bone of more normal-looking architecture had begun to appear. The double line at the superior margin of the pubic ramus had disappeared and was replaced by normal cortex.

\section{Discussion}

Our first problem in this patient was that of diagnosis. His chest condition had been found by routine $x$-ray examination at a time when he was virtually free of symptoms. The $x$-ray finding in turn led to an early diagnosis of sarcoidosis, based on definite histological appearances in an excised axillary lymph node. Plasma calcium determination then revealed severe hypercalcaemia, which surprised us in view of the absence of most of the characteristic symptoms or signs.

Hypercalcaemia has been recognized as a possible complication of sarcoidosis for many years, though its mechanism was at first obscure. Then in 1954 two groups (Anderson et al., 1954 ; Henneman et al., 1956), working independently, concluded almost simultaneously that the cardinal abnormality was an excessive absorption of calcium from the gut, which, taken with the other features of the biochemical disorder, closely resembled vitamin-D overdosage. Anderson et al. suggested that the hypercalcaemia might be the result of sensitivity to vitamin D. Later, one of us (Dent, 1958) reported that hypercalcaemia could be induced in sarcoidosis by the action of ultra-violet light on the skin. During one balance experiment all the metabolic changes during ultra-violet irradiation closely mimicked those of vitamin-D overdosage and all were rapidly reversed by cortisone. Recently other workers (Bell et al., 1964) have produced further evidence of excessive sensitivity to normal amounts of vitamin $D$ in patients suffering from sarcoidosis.

Both Anderson et al. and Henneman et al. noted that the raised plasma calcium rapidly returned to normal under the influence of cortisone. One of us (Dent, 1956) then recommended the use of a standard cortisone test in the differential diagnosis of hypercalcaemia. Further experience has confirmed its value (Dent, 1962 ; Watson, 1964 ; and unpublished observations). Hence when it was found that this patient's hypercalcaemia failed to respond to the administration of prednisone or cortisone it was clear that he might also be suffering from another cause of hypercalcaemia, of which hyperparathyroidism was by far the most likely.

We thought that his bone $x$-ray findings were very much in favour of this, for the hands showed minor but definite changes of hyperparathyroid bone disease. We had seen another patient (Dent and Watson, 1964) with cancer and hyperparathyroidism in whom the $x$-ray changes in the hands were so minimal that they were of diagnostic value only in retrospect, when they had returned to normal after removal of the parathyroid adenoma. Our assessment in the present case was favourably influenced by this earlier experience.

We have studied another patient with sarcoidosis involving the liver whose hypercalcaemia only partly fell with cortisone. $\mathrm{Mr}$. Davies was asked to do a diagnostic exploration of his neck. He found four normal parathyroid glands (Dent, 1962). Subsequently the administration of an equivalent dose of hydrocortisone lowered the patient's plasma calcium to normal, and we have speculated that extensive liver involvement may prevent the adequate conversion of cortisone to the physiologically active hydrocortisone. Though our patient had no evidence of liver disease, we hesitated to make a final diagnosis of sarcoidosis and hyperparathyroidism until we had repeated the cortisone test with an equivalent dose of hydrocortisone $(40 \mathrm{mg}$. every eight hours). The result of the test was quite unequivocalafter a slight rise and fall the plasma calcium was unaltered by hydrocortisone administration.

We also considered the results of his calcium-balance studies in relation to the diagnostic problem. The control periods showed marked overabsorption of calcium from the gut with excessive urinary excretion, a common finding in hyperparathyroidism (Hodgkinson, 1963 ; Lafferty and Pearson, 1963 ; Anderson et al., 1964 ; Dent and Watson, 1964) as in sarcoidosis (Anderson et al., 1954; Henneman et al., 1956). After the administration of hydrocortisone the faecal calcium increased somewhat, while the urinary calcium rose even further before returning to the base-line level again. We considered that this finding, taken with the lack of plasma response, was more in favour of hyperparathyroidism than it was of sarcoidosis as being the main factor influencing his calcium metabolism. It is of interest here to note that he showed no real evidence of vitamin-D sensitivity in the post-operative period, tolerating a 
dose of $2 \mathrm{mg}$. of dihydrotachysterol daily for 15 days, followed by $1 \mathrm{mg}$. daily for a further three and a half months before developing a slightly raised plasma calcium (non-fasting) of 11 mg./100 ml. This observation and the severe hypocalcaemic response post-operatively are also in favour of the view that his calcium metabolic disorder was chiefly the result of hyperparathyroidism. We have learnt from other patients to expect severe tetany post-operatively not only when gross osteitis fibrosa generalisata is present, but also when there is much more localized and limited disease of the cystic form, as in the present case.

Having established the diagnosis of both hyperparathyroidism and sarcoidosis, we had further to consider the possibility of localized Paget's disease of bone in the right pubic ramus as a third diagnosis. This was based largely on the radiological appearances, but these were striking. The expansion of the involved area, its coarsely trabeculated appearance, and the sharp demarcation from surrounding normal bone were thought to be very characteristic of Paget's disease. The post-operative follow-up seems to have given the answer to this particular diagnostic problem. The radiological appearances in the affected area have changed towards normal, while the plasma alkaline phosphatase levels have returned completely to normal. We therefore consider that he had cystic hyperparathyroid bone disease and not Paget's disease, a conclusion which is also in keeping with his severe post-operative tetany.

The finding of sarcoidosis and of primary hyperparathyroidism in this case is of theoretical importance, as it further strengthens the argument based on previous similar experiences that this association is unlikely to to be due to coincidence. Clinical research nowadays on the parathyroid gland is emphasizing more and more how little we know about the aetiology of adenoma and carcinoma formation. The original suggestion of Albright and Reifenstein (1948) that low calcium diet might be a common cause was not supported by the dietary survey conducted in this department (Dent et al., 1961). The finding of parathyroid adenomas in patients with coeliac disease (Davies et al., 1956) and renal failure (Golden et al., 1965) suggested that other causes of parathyroid hyperplasia could occasionally trigger off adenoma formation. Furthermore, we have other evidence (Glanville and Bloom, 1965 ; and unpublished cases) which strongly suggests that this process has been operative in patients with other causes of osteomalacia. All this might be expected. However, clearly it is unlikely that a high proportion of patients with parathyroid adenoma have passed through a phase of osteomalacic disease of any origin. Hence the association of parathyroid adenomas with other diseases not known to produce hyperplasia becomes of importance.

In our series of 80 patients (Dent, 1962) no fewer than 30 had some other serious disease, a far higher proportion than would be expected from a matched control series. We have continued to note this in subsequent cases. Sarcoidosis is clearly one of the rarer associations. Since our knowledge of sarcoidosis itself is so inadequate, we cannot even guess intelligently the nature of this association. We suggest that for the time being a careful record needs to be kept of all the diseases associated with parathyroid adenoma in case some light can later be thrown on the causal relationships. Meanwhile such knowledge will be of value in facilitating the diagnosis in these particularly difficult cases.

\section{Summary}

A case is reported in which the finding of miliary shadows in a routine chest $x$-ray film led to a prompt diagnosis of sarcoidosis and then of hypercalcaemia.

The hypercalcaemia was unaltered by our standard hydrocortisone test. This and other evidence led to the diagnosis of primary hyperparathyroidism as a second condition. A parathyroid adenoma was found and removed from the neck.

The association of hyperparathyroidism and sarcoidosis seems unlikely to be due to chance and is of considerable theoretical interest.

Clearly it is important to bear in mind that in any patient with hypercalcaemia there may be more than one cause operating or appearing to be operating. This situation also seems to occur more often than it should.

Follow-up showed that an area of bone which had characteristic radiological appearances of Paget's disease was more likely to be cystic hyperparathyroid bone disease. This emphasizes the difficulty of radiological diagnosis between the two conditions.

We wish to thank the nurses, biochemists, and dietitians of the metabolic ward for invaluable assistance. One of us (L.W.) gratefully acknowledges receipt of a Fellowship from the British Empire Cancer Campaign.

\section{REFERENCES}

Albright, F., and Reifenstein, E. C. (1948). The Parathyroid Glands and Metabolic Bone Disease. Baillière, Tindall and Cox, London.

Anderson, J., Dent, C. E., Harper, C., and Philpot, G. R. (1954), Lancet, 2, 720 .

Osborn, S. B., Tomlinson, R. W. S., and Wall, M. (1964). Quart. 7. Med., 33, 421 .

Bell, N. H., Gill, J. R., Bartter, F. C., Diller, E., and Smith, H. (1964) Amer. 7. Med., 36, 500 .

Burr, J. M., Farrell, J. J., and Hills, A. G. (1959). New Engl. f. Med., 261,1271 .

Davies, D. R., Dent, C. E., and Willcox, A. (1956). Brit. med. f., 2, 1133.

Dent, C. E. (1956). Ibid., 1, 230.

- (1958). Proc. VIII Middle East Assembly, Beirut, p. 162.

- (1962). Brit. med. F., 2, 1419, 1495.

- Hartland, B. V., Hicks, J., and Sykes, E. D. (1961). Lancet, 2 336.

- and Watson, L. C. A. (1964). Brit. med. F., 2, 218

Glanville, H. J., and Bloom, R. (1965). Ibid., 2, 26. Golden, A., Canary, J. J., and Kerwin, D. M. (1965). Amer. F. Med., Henneman, P. H., Dempsey, E. F., Carroll, E. L., and Albright, F.
(1956). f. clin. Invest., 35, 1229.

Hodgkinson, A. (1963). Clin. Sci., 25, 231.

Lafferty, F. W., and Pearson, O. H. (1963). F. clin. Endocr., 23, 891. Snapper, I., Yarvis, J. J., Freund, H. R., and Goldberg, A. F. (1958).

Watson, L. (1964). Quart. f. Med., 33, 525. 